University of Nebraska - Lincoln

DigitalCommons@University of Nebraska - Lincoln

USDA National Wildlife Research Center - Staff Publications
U.S. Department of Agriculture: Animal and Plant Health Inspection Service

2018

\title{
A conceptual model for the integration of social and ecological information to understand human-wildlife interactions
}

\author{
Stacy A. Lischka \\ Colorado State University, slischka@wcs.org \\ Tara L. Teel \\ Colorado State University \\ Heather E. Johnson \\ USGS, heatherjohnson@usgs.gov \\ Sarah E. Reed \\ Colorado State University \\ Stewart Breck \\ USDA National Wildlife Research Center
}

See next page for additional authors

Follow this and additional works at: https://digitalcommons.unl.edu/icwdm_usdanwrc

Part of the Life Sciences Commons

Lischka, Stacy A.; Teel, Tara L.; Johnson, Heather E.; Reed, Sarah E.; Breck, Stewart; Don Carlos, Andrew; and Crooks, Kevin R., "A conceptual model for the integration of social and ecological information to understand human-wildlife interactions" (2018). USDA National Wildlife Research Center - Staff Publications. 2149.

https://digitalcommons.unl.edu/icwdm_usdanwrc/2149

This Article is brought to you for free and open access by the U.S. Department of Agriculture: Animal and Plant Health Inspection Service at DigitalCommons@University of Nebraska - Lincoln. It has been accepted for inclusion in USDA National Wildlife Research Center - Staff Publications by an authorized administrator of DigitalCommons@University of Nebraska - Lincoln. 


\section{Authors}

Stacy A. Lischka, Tara L. Teel, Heather E. Johnson, Sarah E. Reed, Stewart Breck, Andrew Don Carlos, and Kevin R. Crooks 
Perspective

\title{
A conceptual model for the integration of social and ecological information to understand human-wildlife interactions
}

\author{
Andrew Don Carlos ${ }^{\mathrm{c}}$, Kevin R. Crooks ${ }^{\mathrm{b}}$ \\ ${ }^{a}$ Research, Policy, and Planning Branch, Colorado Parks and Wildlife, 317 W. Prospect Ave., Fort Collins, CO 80526, USA \\ ${ }^{\mathrm{b}}$ Department of Fish, Wildlife, and Conservation Biology, Colorado State University, Fort Collins, CO 80523, USA \\ ${ }^{c}$ Department of Human Dimensions of Natural Resources, Colorado State University, Fort Collins, CO 80523, USA \\ ${ }^{\mathrm{d}}$ Research, Policy, and Planning Branch, Colorado Parks and Wildlife, 415 Turner Dr., Durango, CO 81301, USA \\ e Americas Program, Wildlife Conservation Society, 2300 Southern Blvd., Bronx, NY 10460, USA \\ ${ }^{\mathrm{f}}$ National Wildlife Research Center, USDA Wildlife Services, 4101 Laporte Ave., Fort Collins, CO 80521, USA
}

Stacy A. Lischka ${ }^{\mathrm{a}, \mathrm{b}, *}$, Tara L. Teel ${ }^{\mathrm{c}}$, Heather E. Johnson ${ }^{\mathrm{d}, 1}$, Sarah E. Reed ${ }^{\mathrm{b}, \mathrm{e}}$, Stewart Breck ${ }^{\mathrm{f}}$,

\section{A R T I C L E I N F O}

\section{Keywords:}

Social-ecological systems

Black bears

Carnivores

Social science

Human-bear conflict

Colorado

\begin{abstract}
A B S T R A C T
There is growing recognition that interdisciplinary approaches that account for both ecological and social processes are necessary to successfully address human-wildlife interactions. However, such approaches are hindered by challenges in aligning data types, communicating across disciplines, and applying social science information to conservation actions. To meet these challenges, we propose a conceptual model that adopts a social-ecological systems approach and integrates social and ecological theory to identify the multiple, nested levels of influence on both human and animal behavior. By accounting for a diverse array of influences and feedback mechanisms between social and ecological systems, this model fulfills a need for approaches that treat social and ecological processes with equal depth and facilitates a comprehensive understanding of the drivers of human and animal behaviors that perpetuate human-wildlife interactions. We apply this conceptual model to our work on human-black bear conflicts in Colorado, USA to demonstrate its utility. Using this example, we identify key lessons and offer guidance to researchers and conservation practitioners for applying integrated approaches to other human-wildlife systems.
\end{abstract}

\section{Introduction}

In his prescient work, Wilderness, Aldo Leopold (1949: 188) stated that "One of the anomalies of modern ecology is the creation of two groups, each of which seems barely aware of the existence of the other. The one studies the human community, almost as if it were a separate entity, and calls its findings sociology, economics and history. The other studies the plant and animal community and comfortably relegates the hodge-podge of politics to the liberal arts. The inevitable fusion of these two lines of thought will, perhaps, constitute the outstanding advance of this century." This refrain has become common in the conservation sciences since Leopold's plea (e.g., Mascia et al., 2003), yet researchers and practitioners still struggle to work across disciplinary boundaries to achieve conservation success. Although there is growing recognition that approaches that integrate social and ecological knowledge should lead to more effective and sustained conservation solutions, difficulties in aligning data types, challenges of communicating across disciplines, and misperceptions about the quality and utility of social science information continue to plague these efforts (Fox et al., 2006; Pooley et al., 2014). Nonetheless, the potential for this integration remains a critical advance for the next century of conservation (Tallis and Lubchenco, 2014).

The need for social-ecological integration is readily apparent in the management of human-wildlife interactions (HWIs), defined as the spatial and temporal juxtaposition of human and wildlife activities where humans, wildlife, or both are affected (Leong, 2010; Peterson et al., 2010). Although HWIs are the direct result of human and/or animal behavior, numerous social and ecological factors contribute to the conditions shaping those behaviors, defying single-discipline explanations of causal mechanisms (Dickman, 2010). Understanding the complexity of drivers of HWIs is critical, as the value people place on these interactions ultimately provides the foundation for wildlife conservation and management, whether people want to see interactions enhanced (e.g., increased hunting opportunity, recovery of endangered

\footnotetext{
* Corresponding author at: Rocky Mountain West Program, Wildlife Conservation Society, 212 South Wallace, Suite 101, Bozeman, MT 59715, USA.

E-mail address: slischka@wcs.org (S.A. Lischka).

${ }^{1}$ Current address: U.S. Geological Survey, Alaska Science Center, 410 University Drive, Anchorage, AK, USA 99508.
} 
species) or reduced (e.g., property damage; Riley et al., 2003).

Whereas a number of recent papers have called for integrated approaches to understanding HWIs, particularly in the context of humanwildlife conflict (e.g., Dickman, 2010; Redpath et al., 2013), progress in this area will be facilitated by a comprehensive framework to guide investigations of the diverse array of social and ecological drivers of HWIs. In response to this need, we propose a conceptual model of HWIs that adopts a social-ecological systems (SES) approach. SESs are systems of biophysical and social factors that interact at multiple spatial, temporal, and organizational scales and whose flow is regulated in dynamic and complex ways (Redman et al., 2004). Our model integrates theory from the social and ecological sciences, building upon recent advances applying a systems approach to understand the human dimensions of conservation (e.g., Manfredo et al., 2016). We add to existing frameworks aimed at addressing SES questions (Binder et al., 2013), including previous applications of SES concepts to HWIs (e.g., Morzillo et al., 2014; Carter et al., 2014), by treating social and ecological systems in equal depth, acknowledging the bidirectional influence of social and ecological processes, and considering both individual-level and broad, external influences on human and animal behavior. In doing so, we provide a heuristic framework to assist researchers and practitioners in understanding the relationship between social and ecological drivers of HWIs and foster interdisciplinary approaches to addressing them. We apply the model to our work on human-black bear (Ursus americanus) conflicts to illustrate the benefits of our approach and conclude with a set of lessons learned, offering guidance for applying integrated approaches to other human-wildlife systems.

\section{SES model of human-wildlife interactions}

In the simplest form, HWIs can be conceptualized as the result of two distinct, but interacting systems: social and ecological (Fig. 1a). Although human and animal behaviors are the proximate drivers of HWIs, the context shaping those behaviors is defined by multiple, nested levels of external social and ecological influences (Fig. 1b) and attributes of individual humans and animals (Fig. 1c). When viewed through a single disciplinary lens, these systems may appear to operate independently; however, the ecological and social systems often overlap spatially, and feedbacks among social and ecological drivers (represented by curved arrows in Fig. 1b) are critical determinants of HWIs.

Within the ecological system, wildlife activities are influenced by a suite of internal and external factors occurring across hierarchical levels (Fig. 1b; see Table 1 for definitions of italicized terms). These levels of decreasing organizational complexity - ranging from ecosystems to individuals (Krebs, 2001) - provide the framework within which wildlife activities occur and the context for HWIs. At the broadest level of external influence, ecosystems define interactions between organisms and their abiotic and biotic environment, and prescribe the nature, direction, and distribution of the flow of energy and nutrients. At the next level, ecological communities determine interactions among species through processes such as predation and competition, further constraining the distribution and behavior of individual animals. The last tier of external influence occurs at the population level, where local dynamics influence the abundance, density, survival, and reproduction of individuals, which in turn, can strongly affect animal behavior. In addition to these external influences, individual behavior is the consequence of various individual attributes of animals (Fig. 1c). Attributes such as demographic characteristics (e.g., age, sex), reproductive status, physiological condition, social status, temperament, previous experience, and genes can all shape animal behavior directly or indirectly (Davies et al., 2012).

Mirroring the multilevel conceptualization of the ecological system, human activities are affected by external and internal influences within the social system (Manfredo et al., 2014, 2016; Fig. 1b, c; Table 1). At the broadest level, patterns in society, such as language, culture, economic development, and human migration, shape the context within which people live and interact with the natural environment. Institutions and governance structures, such as decision-making authority, policies, and methods for public engagement, comprise the next level of external influence and affect people's perceptions and expectations about decision-making processes, power, and resource allocation. At the finest level of external influence, groups, such as community organizations and other affiliations with which people identify, impose and reinforce norms for acceptable behavior in relation to one's social and environmental surroundings. Individual behavior is also driven by various individual attributes (Fig. 1c), ranging from general (values) to specific (attitudes, personal norms) cognitive influences, as well as socio-demographic characteristics, emotions, previous experience, and genes. Although traditional approaches to understanding conservation-related behaviors have assumed that rational choice and cognitive influences guide individual actions, recent advances call for greater attention to non-cognitive (e.g., emotions) and broader-level (e.g., groups, institutions) factors captured by our model (Manfredo et al., 2014, 2016).

By explicitly acknowledging the suite of external and internal factors operating within both the social and ecological systems, researchers are better able to identify the relative roles of each in driving HWIs, and importantly, account for spatial overlap and feedbacks within and between the two interacting systems (Redman et al., 2004; Manfredo et al., 2016). For example, ecosystem characteristics, such as the location of rivers and streams, can affect animal distribution, as well as patterns of human migration and residential development, which are societal-level drivers. Institutional influences, such as decisions to reintroduce a threatened species, can alter predator-prey dynamics within ecological communities and affect human attitudes by impacting people's wildlife-related experiences. In addition to these top-down and crosssystem effects, individual human and animal behaviors can scale up through both social and ecological systems to affect processes occurring at higher levels. For example, collective human actions can affect institutional response, as when voting behavior on state referenda limits the methods that wildlife agencies can use to manage species. As illustrated in the case study below, our model can serve as a conceptual map to facilitate conversations across disciplines about information gaps, research questions, and management strategies that better account for the complex and dynamic nature of HWIs.

\section{Case study: applying the conceptual model to understand drivers of human-black bear conflicts}

\subsection{Background}

Although interactions between humans and black bears can be positive, they often result in threats to human property and safety (e.g., bears breaking into vehicles), nuisances (e.g., spilled trash; Gore et al., 2006a), and increased bear mortality (e.g., lethal removal; Treves and Karanth, 2003). As human development has encroached on bear habitat, conflicts resulting from bears foraging for anthropogenic food near human development (e.g., garbage and fruit trees; Lewis et al., 2015) have increased (Hristienko and McDonald, 2007), becoming a major management challenge for wildlife agencies. Although wildlife agencies have invested significant resources in a variety of approaches to reduce conflicts, such as translocation, education, and harvest, these efforts have generally yielded limited success in reducing conflicts in residential settings (Gore et al., 2006b; Treves et al., 2010; BaruchMordo et al., 2011). Investigators recognize that both ecological and social factors contribute to human-bear conflicts (Baruch-Mordo et al., 2009), yet few studies have attempted to integrate both types of information to guide management.

As part of a large-scale study to better understand both the ecological and social factors associated with increases in human-bear conflicts, several authors of this paper conducted an experiment in 
a)

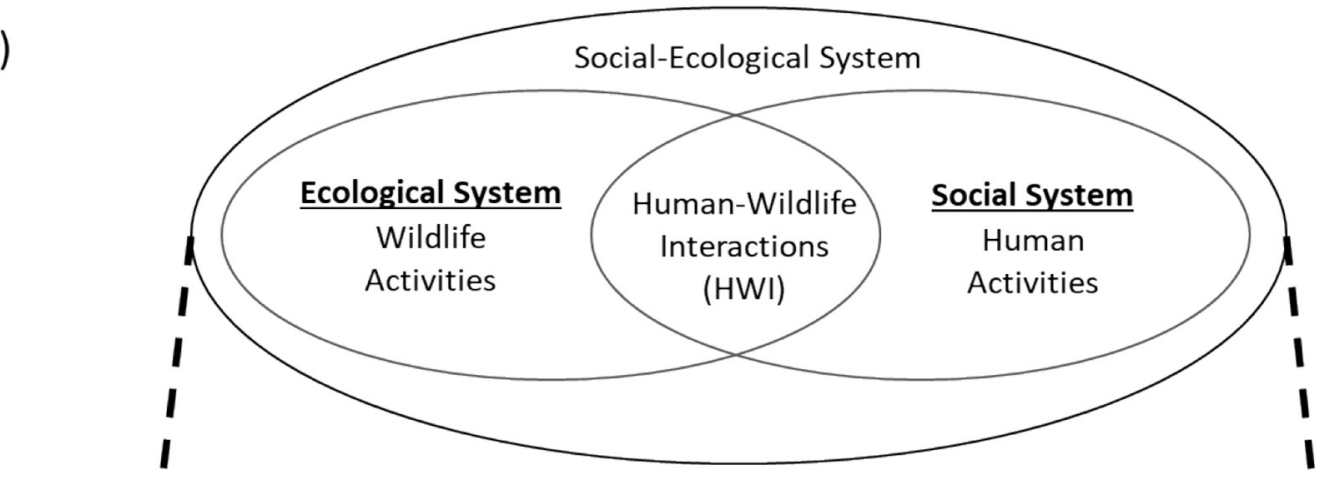

b)

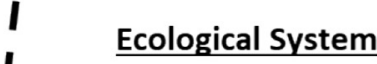

Wildlife Activities

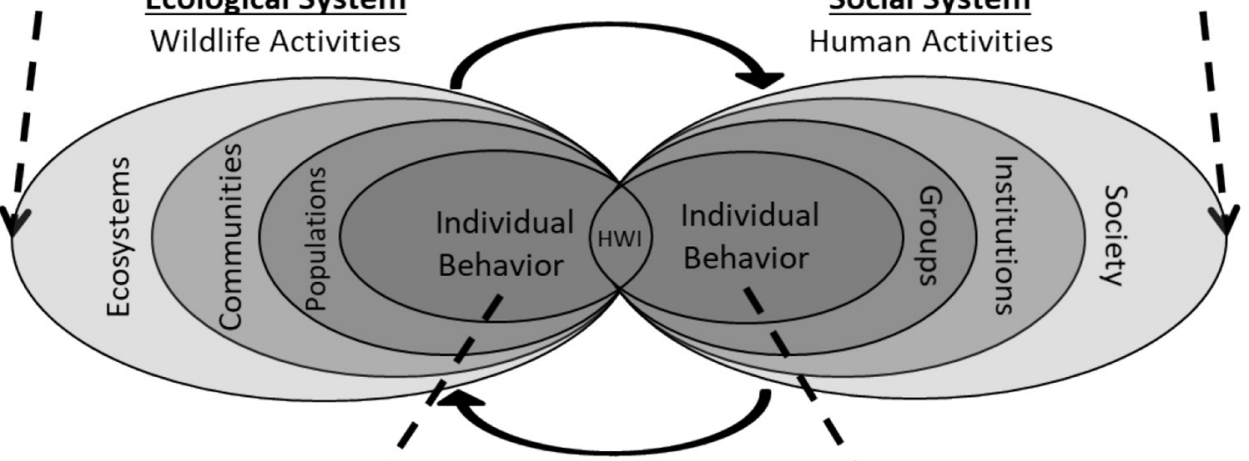

c)

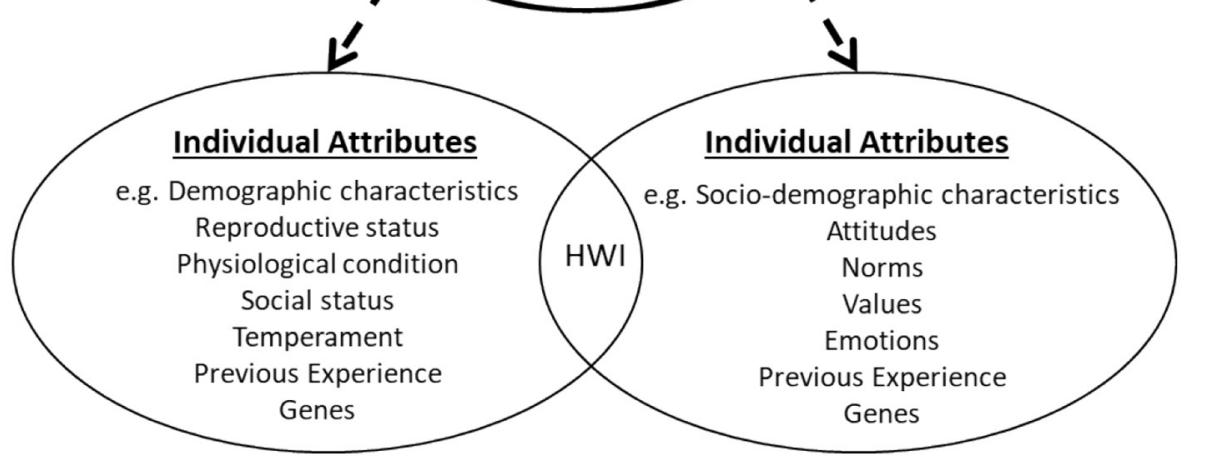

Fig. 1. SES model of human-wildlife interactions. Selected concepts from this figure are defined in Table 1. Panel a) describes the overall SES model of HWIs, while panel b) describes external influences on individual behavior, and panel c) describes individual attributes which also affect behavior. Curved arrows in b) indicate feedback among all levels of the social and ecological systems.

Durango, Colorado (2011-2106), a community that regularly experiences high human-bear conflict rates (Baruch-Mordo et al., 2008). Because conflicts typically occur when bears use human development to forage on garbage (Lewis et al., 2015), we tested the effectiveness of wide-scale urban bear-proofing for reducing human-bear conflicts (Johnson et al., 2018). Using a before-after-control-impact study design, we distributed 1110 bear resistant garbage containers to all residents of two treatment areas within Durango, and paired these with two control areas where residents did not receive containers. We then monitored garbage-related conflict rates with direct observations of spilled garbage, human attitudes with mail surveys, and human behavior (i.e., appropriate use of the garbage containers) with direct observations. Using this design, our goals were to evaluate the effectiveness of distributing bear-resistant containers for reducing human-bear conflicts, identify the social and ecological factors contributing to conflicts, and assess the outcomes of this action on human behaviors and attitudes (Johnson et al., 2018). Our experiences planning and executing this project, as well as conversations with colleagues working on similar projects in other ecosystems, led to development of the conceptual model presented in this paper. Our successes and failures helped us refine the components of the model, and serve as a meaningful example of the ways its application can foster a broad understanding of the drivers of human-wildlife conflicts.

\subsection{Defining components of the model}

Within the ecological system, a suite of external factors and individual attributes shape bear behaviors that contribute to garbage-related conflicts between people and bears (see Table 1 for case study examples). The ecosystems around Durango are diverse, with widely varying elevations, climate conditions, and vegetation types, dominated by ponderosa pine (Pinus ponderosa), Gambel oak (Quercus gambelii), aspen (Populus tremuloides), pinyon pine (Pinus edulis), juniper (Juniperus spp.), and mountain shrubs (e.g., Prunus virginiana, Amelanchier alnifolia). The resulting ecological communities provide a diversity of plants and animals that produce natural foods for black bears, such as grasses, forbs, berries, acorns, and insects. Natural food abundance is highly variable across years due to annual variation in weather (e.g., drought conditions, late freezes), and scarcity in natural foods can cause bears to increase their use of human development (Johnson et al., 2015, 2017). For example, during a poor natural food year in 2012, bears around Durango increased their use of development and the population was estimated to have declined in association with high rates of humancaused mortality (e.g., vehicle collisions, harvest, lethal removals of 
Table 1

Definitions of selected terms in the conceptual model of human-wildlife interactions.

\begin{tabular}{|c|c|c|}
\hline Term & Definition & Case study examples \\
\hline Human-wildlife interactions $s^{\mathrm{a}, \mathrm{b}}$ & $\begin{array}{l}\text { Spatial and temporal juxtaposition of wildlife and human activities where } \\
\text { humans, wildlife, or both are affected }\end{array}$ & $\begin{array}{l}\text { Black bears forage on unsecured human garbage; Humans see } \\
\text { black bear while walking in a city park }\end{array}$ \\
\hline \multicolumn{3}{|l|}{ Ecological system ${ }^{\mathrm{c}, \mathrm{d}}$} \\
\hline Ecosystem & Interacting biotic and abiotic components of the environment & $\begin{array}{l}\text { Climate conditions and vegetation types that influence habitat for } \\
\text { bears }\end{array}$ \\
\hline Community & $\begin{array}{l}\text { Suite of species that populate a given area and interact through activities } \\
\text { such as competition and predation }\end{array}$ & $\begin{array}{l}\text { Availability of key plant species that provide natural foods for } \\
\text { bears }\end{array}$ \\
\hline Population & Members of a single species that interact and interbreed & $\begin{array}{l}\text { Survival, reproduction, immigration, and emigration rates that } \\
\text { influence bear abundance and distribution }\end{array}$ \\
\hline Individual behavior & $\begin{array}{l}\text { Actions of individual animals that provide the opportunity to interact with } \\
\text { humans }\end{array}$ & Foraging of black bears in urban areas for anthropogenic foods \\
\hline Physiological condition & $\begin{array}{l}\text { Mechanical, physical, and biochemical processes that affect survival and } \\
\text { reproduction }\end{array}$ & $\begin{array}{l}\text { Increased caloric intake by bears in preparation for hibernation } \\
\text { (e.g., hyperphagia) }\end{array}$ \\
\hline Social status & Ranking system created when members of a social group interact & Differential access to natural food sources based on dominance \\
\hline Temperament & $\begin{array}{l}\text { Within species differences in behavioral tendencies that are consistent over } \\
\text { time and correlated across contexts }\end{array}$ & $\begin{array}{l}\text { Behaviors such as boldness that make bears more likely to explore } \\
\text { novel habitats (i.e., human-dominated areas) }\end{array}$ \\
\hline \multicolumn{3}{|l|}{ Social system ${ }^{\mathrm{e}, \mathrm{f}}$} \\
\hline Society & $\begin{array}{l}\text { Broad social forces that act on large groups of humans such as culture, } \\
\text { language, and patterns of human migration }\end{array}$ & $\begin{array}{l}\text { Technological advances that allow workers to live farther from } \\
\text { traditional workplaces }\end{array}$ \\
\hline Institutions & $\begin{array}{l}\text { Formal and informal decision-making processes that distribute power and } \\
\text { allocate resources }\end{array}$ & $\begin{array}{l}\text { City ordinances that require trash to be secured from bears and } \\
\text { other wildlife }\end{array}$ \\
\hline Groups & $\begin{array}{l}\text { Formal and informal associations among humans that define and reinforce } \\
\text { norms }\end{array}$ & $\begin{array}{l}\text { Groups interested in and affected by wildlife-human conflict } \\
\text { issues such as homeowners associations }\end{array}$ \\
\hline Individual behavior & $\begin{array}{l}\text { Actions of individual humans that provide the opportunity to interact with } \\
\text { wildlife }\end{array}$ & Storage of garbage and other food attractants \\
\hline Attitudes & Directional evaluation of a specific object or event, based on memory & $\begin{array}{l}\text { Support for management actions to euthanize conflict-causing } \\
\text { bears }\end{array}$ \\
\hline Values & $\begin{array}{l}\text { Fundamental, stable goals and principles that transcend situations and guide } \\
\text { human behavior }\end{array}$ & Belief that wildlife are deserving of rights and care \\
\hline Norms & $\begin{array}{l}\text { Rules that define acceptable behaviors in social life; Enforced directly by } \\
\text { group members or by personal perceptions of group expectations }\end{array}$ & Expectations about how neighbors should store their garbage \\
\hline Emotions & $\begin{array}{l}\text { Short duration feeling states elicited by a specific situation and that occupy } \\
\text { conscious thought }\end{array}$ & Fear elicited when a person encounters a bear near home \\
\hline \multicolumn{3}{|l|}{ a Leong (2010). } \\
\hline \multicolumn{3}{|l|}{ b Peterson et al. (2010). } \\
\hline \\
\hline \multicolumn{3}{|l|}{ d Davies et al. (2012). } \\
\hline \multicolumn{3}{|c|}{ e Manfredo et al. (2014, 2016). } \\
\hline \multicolumn{3}{|c|}{ f Manfredo (2008). } \\
\hline
\end{tabular}

conflict-involved individuals; Laufenberg et al., 2018). In addition to these external factors, several individual attributes are known to influence bear foraging behavior around human development, and thus, their probability of accessing human foods and interacting with people. For example, Johnson et al. (2015) found that female bears that were older, had limited access to natural foods, and were experiencing hyperphagia (the period of increased foraging prior to hibernation) selected more strongly for human development.

Individual human behaviors also contribute to human-bear interactions, especially those related to the storage of garbage and other food attractants (Table 1; Johnson et al., 2018). Societal forces around Durango, a rapidly growing, mid-sized city in southwest Colorado, affect patterns of residential development. Durango is surrounded by public lands popular for outdoor recreation, which attracts many new residents. The resulting development, aided by technological advancements in communications that allow people to live farther from traditional workplaces, has occurred within areas that were high-quality bear habitat (Johnson et al., 2015), increasing the availability of human foods on the landscape. Institutional factors include actions taken by local, state, and federal authorities to reduce conflicts and alter the distribution of bears. Wildlife managers have increased bear harvest in response to high rates of reported conflict, and the city implemented an ordinance requiring people to secure trash from bears and other wildlife (http://www.durangogov.org/index.aspx?NID =668). Based on our systematic observations of bear-resistant garbage containers distributed as a part of the project, we found that resident use of the containers was highly variable. On some blocks, all residents kept garbage secured in provided containers, while on other blocks, few to no residents did so (Johnson et al., 2018), suggesting that social norms (i.e., perceived social pressure to behave in a certain way) about garbage storage may also be variable. A suite of individual attributes (e.g., values, attitudes, personal norms [i.e., personal expectations about how one ought to behave]) also play a role in determining human behaviors related to garbage storage. For example, using mail survey data, we found that individuals who believe that the state wildlife management agency is trustworthy and capable of addressing negative interactions between people and bears, representing positive attitudes toward the agency, are less likely to take individual action (e.g., bear-proofing garbage) to reduce their risk of human-bear interactions (Colorado Parks and Wildlife, unpublished data). In contrast, residents with negative attitudes toward the agency believe that their own individual action is required to reduce human-bear conflicts, and, therefore, are more likely to keep their garbage secured. Additional influences, such as fearful emotions elicited from encounters with bears, may also motivate bearproofing behaviors (Wieczorek Hudenko, 2012).

The Durango system also illustrates how spatial overlap of social and ecological drivers, and feedback between them, can affect the likelihood of interactions between humans and bears. Feedback between social and ecological dynamics can perpetuate garbage-related conflicts, complicating efforts to reduce negative interactions while maintaining sustainable bear populations along the wildland-urban interface. Most notably, individual human behaviors that make garbage and other food sources accessible to bears can directly alter the behavior of individual bears by providing abundant, alternate food sources. In 
fact, as bears increased their use of human food in Durango, they decreased their hibernation and were thus awake to interact with people for more time during the year (Johnson et al., 2017), further illustrating how human behavior can alter bear behavior and the potential for conflict. Foraging in human-dominated areas can also increase mortality risks to bears from vehicle collisions, conflict removals, and other sources (Beckmann and Berger, 2003; Hostetler et al., 2009). For example, Laufenberg et al. (2018) detected a 57\% decline in the female bear population surrounding Durango following a year of poor natural food conditions. This decline was primarily driven by increased mortality from bear-vehicle collisions as bears increased foraging within development, and resulted in dramatic changes to the distribution of bears in areas near Durango. Further, tolerance, an attitude which is often used to describe social acceptance of wildlife species (Bruskotter and Wilson, 2014), is determined by both positive and negative interactions with individuals of the species (Zajac et al., 2012; Lischka et al., 2008). Because bear behavior changes with the abundance of natural foods, these changes also have the potential to impact where and how often people interact with bears. If reductions in positive interactions occur, feedback between the social and ecological systems may yield lower tolerance for bears among residents, ultimately affecting support for bear conservation (Bruskotter and Wilson, 2014). Feedback between the social and ecological systems can also result from efforts to reduce garbage-related conflicts. For example, increasing the rate of bearproofing within residential areas (individual human behavior) appears to cause a decrease in the amount of time bears spend foraging in town (individual bear behavior; Johnson et al., 2018). This reduction can motivate institutional actions, such as occurred in Durango when the city government decided to provide no-cost bear-resistant containers to residents in a larger area of town, following completion of this project.

\section{Lessons learned from the case study}

Our Durango research team experienced several challenges in our attempts to execute an integrated SES investigation of human-bear conflicts. As research progressed, we realized that a conceptual framework could assist us in addressing many of these challenges, so we developed the model presented herein. As we modified and executed research plans to achieve a more fully integrated study, we identified ways that its application could help us in understanding the system and refined the model. The model helped us identify areas where we could improve the project and its outcomes, albeit sometimes in hindsight, and we learned several valuable lessons as we worked toward an integrated social-ecological study. The lessons described below are not unique to HWIs, SES efforts more broadly (Pooley et al., 2014), or even to measuring the concepts we describe in this model, but, rather, are common to interdisciplinary studies that combine social and ecological data. We hope that the lessons we learned will help other multidisciplinary research teams better anticipate and resolve such challenges and thereby foster more effective integration of social and ecological information, no matter the conservation context.

\subsection{Lesson 1: Integrate social science throughout the research process}

The success of integrated approaches to understanding and managing HWIs is dependent on the extent to which they adequately address social factors (Dickman, 2010), yet wildlife research and management typically focus on actions that modify animal populations (Morzillo et al., 2014). Because ecologists may lack familiarity with how the social sciences can contribute to conservation, social science experts are often not included on research teams or not incorporated sufficiently early in the process (Pooley et al., 2014). Further, on such a team, a single social scientist may be expected to represent a variety of disciplinary specialties, as ecologists may not recognize distinct specializations within the broader field (Bennett et al., 2016). However, as with the ecological realm where there are specialized disciplines, theory, and expertise at each of the scales from individual to ecosystem, the same is true within the social realm. Including representatives on the project team from a variety of social science disciplines would help ensure that the appropriate theories, processes, and impacts are considered and addressed, across the levels of influence identified by the model.

Even when social and ecological scientists collectively design research objectives, teams often separate into discipline-specific groups to collect and analyze data and disseminate results. Although it requires a significant investment of time and effort and a willingness to make continued adjustments to approaches along the way, the outcomes of truly integrated work can have surprising results that independent efforts would otherwise miss. For example, although our conceptual model recognizes the importance of social and ecological factors in driving HWIs, our Durango study was initially designed solely to investigate the influence of distributing bear-resistant garbage containers on rates of garbage-related human-bear conflicts. Initially, there was no plan to explicitly understand human behavior or the internal or external influences affecting behaviors. The original research team assumed that the primary impediment to bear-proofing was the cost of bear-resistant garbage containers, and that once residents received a free container, they would use it appropriately. As a result, the primary response variable that was going to be monitored was rates of garbage-related conflicts. After initial study plans were developed, however, social scientists were added to the team. They advocated for monitoring whether residents were using containers properly (manually locking the containers) as well as motivations for doing so. After observing human behavior at $>700$ residences that received free bear-resistant containers, we learned that $<50 \%$ of residents properly locked their containers (Colorado Parks and Wildlife, unpublished data). It became clear that simply measuring conflict rates was not adequate to determine the effect of distributing bear-resistant containers, and that understanding human behavior would be imperative to translating research results into management recommendations. The early inclusion of social science expertise was therefore critical to identify solutions to conflicts that account for both human and animal behavior.

It is not sufficient, however, to simply quantify patterns in human behaviors to supplement understanding of ecological processes. To truly understand and address the dynamics of SESs, researchers must strive for greater depth and integration of findings across the ecological and social realms. In particular, we have faced difficulty identifying the best approach to describe both social and ecological patterns to potentially unfamiliar audiences within publications. Broadening communications to discuss both social and ecological outcomes exposes specialists to the utility of considering multidisciplinary approaches to addressing HWIs. Yet, even within our team, communicating concepts, methods, and findings across disciplines at times proved challenging. Prior work has described similar challenges in applying multidisciplinary approaches to conservation and identified the importance of employing concrete processes to anticipate and address these issues (e.g. Heemskerk et al., 2003; Fox et al., 2006; Pooley et al., 2014). Specifically, we feel that group model development, long-term investment of time and resources in collaborations, and frequent communication with collaborators across disciplines could facilitate the success of integrated projects.

\subsection{Lesson 2: Align the scale of social and ecological data}

The default extent and resolution of data collected in social and ecological studies often do not match, leading to difficulties in integrating findings across data types (Heemskerk et al., 2003; Pooley et al., 2014). This issue can be especially challenging for wide-ranging animals, such as large carnivores. For example, in our case study, researchers fit individual bears with GPS telemetry collars to understand habitat selection and space use with respect to human development (Johnson et al., 2015, 2017). Ideally, as a part of our experiment, we would have provided free bear-resistant garbage containers across the 
same area inhabited by our collared sample of bears to quantify the effects of bear-proofing on bear behavior and garbage-related conflicts. However, financial and logistical constraints hampered our ability to execute the experiment at this scale, primarily due to the large size of bear home ranges and the high cost of bear-resistant containers. As a result, our bear-proofing study was constrained to track the effect of the new containers on conflict rates and human behaviors within the core residential area of Durango. Although this study area was small from an ecological perspective, we were able to concurrently investigate the social and ecological drivers of human and bear behavior that produced conflicts at a spatial scale relevant to HWIs. This scale enabled us to understand feedback mechanisms between human and animal behavior and describe the complex interplay of social and ecological forces that perpetuate conflict.

In addition to aligning the spatial extent of our measures of human and animal behavior, we also modified our plans to assess the motivations for bear-proofing behavior. Initially, we had planned to distribute mail surveys to a random sample of Durango residents to summarize attitudes and behaviors at the scale of the community. However, we recognized that the practice of relying on a random sample to generalize findings to the entire community, a common approach in survey research, would have limited our ability to explore resident motivations at finer degrees of resolution, at the same locations where we were observing bear-proofing behavior and garbage-related conflicts. We also recognized that the experience of garbage-related conflict is heterogeneous across the landscape, likely due to differences in garbage storage behaviors and proximity to bear habitat, and we wanted to understand how ecological factors identified in the conceptual model (e.g., ecosystem, community-level influences) affected human attitudes and behaviors. To address this, we modified social science research plans to sample at a much higher rate, contacting all residents within the community. Furthermore, we recorded survey responses with respect to specific parcel locations, so that we could spatially link them to locations of conflicts, compliance, and ecological variables. Increasing the intensity of our data collection enabled us to model human behavior at a fine resolution and thereby relate the same set of explanatory variables (e.g., distance to riparian habitat) to bear behaviors, human behaviors, and rates of bears accessing garbage. Efforts such as these that match the scale and resolution of data types prior to the start of data collection can overcome common challenges of SES research and yield greater opportunities for integration of results (Pooley et al., 2014).

\subsection{Lesson 3: Conservation means human and animal behavior}

In his influential paper, Conservation Means Behavior, Schultz (2011) argued that conservation success is dependent on efforts to understand and affect human behavior. We agree that these efforts are critical, and further suggest that they be combined with investigations of the drivers and consequences of animal behavior to yield more comprehensive and effective management actions (Blumstein and Fernández-Juricic, 2010). For this reason, the intersection of human and animal behaviors are the primary focus of the conceptual model presented here (Fig. 1).

Wildlife managers have often used rates of HWIs as an indicator of the size of wildlife populations (Morzillo et al., 2014). Consequently, management actions to reduce conflict, such as increased harvest, are frequently aimed at decreasing wildlife population size. Unfortunately, these efforts are rarely successful as conflict rates do not necessarily reflect numerical changes in populations (Treves et al., 2010; Obbard et al., 2014), particularly when animals shift their behavior in response to changing environmental conditions (Wong and Candolin, 2015). For example, in our case study, bear foraging behavior has been found to be highly dynamic, as bears increase their use of anthropogenic foods in poor natural food years and decrease it in good natural food years, as a function of changing forage-risk trade-offs (Johnson et al., 2015). Baruch-Mordo et al. (2013) suggested that managers may be able to reduce forage benefits around development by securing garbage and other attractants. As a result, managers may be able to tip the balance of the forage-risk trade-off, discouraging bears from using human development and reducing garbage-related conflict. In Durango, human-bear conflicts decreased as compliance with the bear-proofing ordinance increased, with reductions in conflict leveling out once $60 \%$ of residents complied with the ordinance (Johnson et al., 2018). This suggests that reductions in forage benefits for bears can indeed have significant effects on nuisance bear behavior. Further, an understanding of how the temperament of individual bears (e.g., degree of boldness) affects use of anthropogenic foods could offer novel approaches to managing HWIs (Blackwell et al., 2016). We suggest that understanding and managing the behavior of individual animals responsible for conflict may be an important improvement in addressing HWIs.

Similarly, social science research on HWIs could benefit from greater attention to quantifying individual human behaviors. Data collection in this area has often relied on passive means of behavioral assessment, including surveys of behavioral intentions or self-reported activities as proxies for actual behavior (Baumeister et al., 2007). While these methods are cost-efficient and can be used to collect information from a large sample of residents, such data may not accurately reflect the frequency of human behaviors (Miller and Anderson, 2002; Wilbur et al., 2018). Direct observation of behaviors can provide more accurate and reliable measures of the prevalence of activities contributing to and resulting from HWIs (Baruch-Mordo et al., 2009), yet are more difficult to collect and are only feasible for behaviors generally observable to the public. In the first year of data collection, we observed that only $50 \%$ of Durango residents appropriately used project-supplied garbage containers, while $>70 \%$ of survey respondents reported doing so (Colorado Parks and Wildlife, unpublished data). By collecting data on bearproofing behaviors through direct observations of garbage containers, rather than relying on self-reports, we were able to quantify rates of over-reporting and better understand the volume of garbage available to bears. As a whole, our experience indicates that accurate information about both animal and human behavior is needed to pinpoint the various drivers of HWIs and identify options for successful management intervention.

\section{Conclusions}

The conceptual model presented herein offers an integrated, multilevel approach to understanding HWIs that acknowledges the critical role of both social and ecological drivers as well as feedbacks among system components. While a number of studies have investigated human-black bear conflicts (e.g., Don Carlos et al., 2009; Kretser et al., 2009; Merkle et al., 2011; Beckmann and Berger, 2003), prior efforts have largely focused on either the social or ecological aspects of conflict and rarely integrated both information types to gain a holistic understanding of the system. This is typical of other HWI systems, where attempts to simultaneously examine both human and animal drivers are rare (Dickman, 2010). By understanding the relative role of social and ecological factors affecting HWIs, as facilitated by the conceptual model we propose, researchers will be in a better position to inform management actions focused on the most critical drivers, whether those are social, ecological, or both.

An additional benefit of taking an SES approach to HWIs is the explicit focus on feedbacks within and across the social and ecological systems. The application of our model to the study of human-black bear conflicts in Durango led to the identification of relationships and feedback mechanisms that had been previously unexplored. We realized that we could not fully evaluate the efficacy of a bear-proofing effort by only tracking changes in human-bear interactions. To more completely assess the effectiveness of changes in waste management practices, we needed to also investigate the importance of natural food conditions, resident compliance with the city bear-proofing ordinance, and the factors motivating those behaviors. Further, by examining the 
social and ecological systems in tandem, we were able to better understand the social and ecological outcomes of human-bear conflicts, such as changes in bear behavior caused by garbage-storage practices and how the experience of conflict affects tolerance for bears. While resulting recommendations will still require institutional support to be put into practice, we hope that this integrated approach will yield improved mitigation of human-bear conflict in the future.

We recommend applying this model to other assessments of HWIs to guide interdisciplinary communication and research efforts that can more adequately address the complex and dynamic nature of humanwildlife relationships. Moreover, applying this framework to a diverse suite of HWI systems, such as illegal wildlife harvest or damage to agricultural products, will contribute to our overall understanding of the relative importance of social and ecological drivers in perpetuating conflict situations, yielding a broader suite of management actions that modify both human and animal behaviors. Our hope is that employing this model and adapting it for use across systems and contexts will move the practice of conservation one step closer to achieving Leopold's (1949) vision of an integrated field of social-ecological inquiry.

\section{Acknowledgements}

This project was funded by Colorado Parks and Wildlife, USDA National Wildlife Research Center, Anheuser-Busch Environmental Fellowship, and Hill Memorial Fellowship. We thank G. Wittemyer for his constructive review, which improved the quality of the manuscript. The survey and administration procedures were approved for use with human subjects prior to implementation (CSU IRB protocol 005-17H). Black bear care and handling procedures were approved for use with animals prior to implementation (Colorado Parks and Wildlife Animal Care and Use Protocol \#01-2011).

\section{Role of the funding source}

This project was funded by Colorado Parks and Wildlife, USDA National Wildlife Research Center, Anheuser-Busch Environmental Fellowship, and Hill Memorial Fellowship. Researchers at Colorado Parks and Wildlife and USDA National Wildlife Research Center designed the study, conducted data collection and analysis, and interpreted data.

\section{References}

Baruch-Mordo, S., Breck, S.W., Wilson, K.R., Theobald, D.M., 2008. Spatiotemporal distribution of black bear-human conflicts in Colorado. J. Wildl. Manag. 72, 1853-1862.

Baruch-Mordo, S., Breck, S.W., Wilson, K.R., Broderick, J., 2009. A tool box half full: how social science can help solve human-wildlife conflict. Hum. Dimens. Wildl. 14, 219-223.

Baruch-Mordo, S., Breck, S.W., Wilson, K.R., Broderick, J., 2011. The carrot or the stick? Evaluation of education and enforcement as management tools for human-wildlife conflicts. PLoS One 6, e15681.

Baruch-Mordo, S., Webb, C.T., Breck, S.W., Wilson, K.R., 2013. Use of patch selection models as a decision support tool to evaluate mitigation strategies of human-wildlife conflict. Biol. Conserv. 160, 263-271.

Baumeister, R.F., Vohs, K.D., Funder, D.C., 2007. Psychology as the science of self-reports and finger movements: whatever happened to actual behavior? Perspect. Psychol. Sci. 2, 396-403.

Beckmann, J.P., Berger, J., 2003. Rapid ecological and behavioural changes in carnivores: the responses of black bears (Ursus americanus) to altered food. J. Zool. 261, 207-212.

Bennett, N.J., et al., 2016. Mainstreaming the social sciences in conservation. Conserv. Biol. http://dx.doi.org/10.1111/cobi.12788.

Binder, C., Hinkel, J., Bots, P., Pahl-Wostl, C., 2013. Comparison of frameworks for analyzing social-ecological systems. Ecol. Soc. 18, 26-44.

Blackwell, B.F., DeVault, T.L., Fernández-Juricic, E., Gese, E.M., Gilbert-Norton, L., Breck, S.W., 2016. No single solution: application of behavioural principles in mitigating human-wildlife conflict. Anim. Behav. http://dx.doi.org/10.1016/j.anbehav.2016. 07.013 .

Blumstein, D.T., Fernández-Juricic, E., 2010. A Primer of Conservation Behavior. Sinauer Associates, Inc., Sunderland, Massachusetts.

Bruskotter, J.T., Wilson, R.S., 2014. Determining where the wild things will be: using psychological theory to find tolerance for large carnivores. Conserv. Lett. 7, 158-165.

Carter, N.H., Viña, A., Hull, V., McConnell, W.J., Axinn, W., Ghimire, D., Liu, J., 2014.
Coupled human and natural systems approach to wildlife research and conservation. Ecol. Soc. 19, 43-60.

Davies, N.B., Krebs, J.R., West, S.A., 2012. An Introduction to Behavioural Ecology, 4th edition. John Wiley and Sons, Hoboken, New Jersey.

Dickman, A.J., 2010. Complexities of conflict: the importance of considering social factors effectively resolving human-wildlife conflict. Anim. Conserv. 13, 458-466.

Don Carlos, A.W., Bright, A.D., Teel, T.L., Vaske, J.J., 2009. Human-black bear conflict in urban areas: an integrated approach to management response. Hum. Dimens. Wildl. $14,174-184$.

Fox, H.E., Christian, C., Nordby, J.C., Pergams, O.R.W., Peterson, G.D., Pyke, C.R., 2006 Perceived barriers to integrating social science and conservation. Conserv. Biol. 20, 1817-1820.

Gore, M.L., Knuth, B.A., Curtis, P.D., Shanahan, J.E., 2006a. Stakeholder perceptions of risk associated with human-black bear conflicts in New York's Adirondack Park campgrounds: implications for theory and practice. Wildl. Soc. Bull. 34, 36-43.

Gore, M.L., Knuth, B.A., Curtis, P.D., Shanahan, J.E., 2006b. Education programs for reducing American black bear-human conflict: indicators of success? Ursus 17 , 75-80.

Heemskerk, M., Wilson, K., Pavao-Zuckerman, M., 2003. Conceptual models as tools for communication across disciplines. Conserv. Ecol. 7, 13.

Hostetler, J.A., McCown, J.W., Garrison, E.P., Neils, A.M., Barrett, M.A., Sunquist, M.E., Simek, S.L., Oli, M.K., 2009. Demographic consequences of anthropogenic influences: Florida black bears in north central Florida. Biol. Conserv. 142, 2456-2463.

Hristienko, H., McDonald, J.E., 2007. Going into the 21(st) century: a perspective on trends and controversies in the management of the American black bear. Ursus 18, $72-88$.

Johnson, H.E., Breck, S.W., Baruch-Mordo, S., Lewis, D.L., Lackey, C.W., Wilson, K.R., Broderick, J., Mao, J.S., Beckmann, J.P., 2015. Shifting perceptions of risk and reward: dynamic selection for human development by black bears in the western United States. Biol. Conserv. 187, 164-172.

Johnson, H.E., Lewis, D.L., Verzuh, T.L., Wallace, C.F., Much, R.M., Willmarth, L.K., Breck, S.W., 2017. Human development and climate affect hibernation in a large carnivore with implications for human-carnivore conflicts. J. Appl. Ecol. http://dx. doi.org/10.1111/1365-2664.13021.

Johnson, H.E., Lewis, D.L., Lischka, S.A., Breck, S.W., 2018. Assessing ecological and social outcomes of a bear-proofing experiment. J. Wildl. Manag. http://dx.doi.org/ 10.1002/jwmg. 21472.

Krebs, C.J., 2001. Ecology: The Experimental Analysis of Distribution and Abundance. Harper \& Row, New York.

Kretser, H.E., Curtis, P.D., Francis, J.D., Pendall, R.J., Knuth, B.A., 2009. Factors affecting perceptions of human-wildlife interactions in residential areas of northern New York and implications for conservation. Hum. Dimens. Wildl. 14, 102-118.

Laufenberg, J., Johnson, H.E., Doherty, P.F., Breck, S.W., 2018. Compounding effects of human development and a natural food shortage on a large carnivore population along a human development-wildland interface. Biol. Conserv. 224, 188-198.

Leong, K.M., 2010. The tragedy of becoming common: landscape change and perceptions of wildlife. Soc. Nat. Resour. 23, 111-127.

Leopold, A., 1949. A Sand County Almanac and Sketches Here and There. Oxford University Press, New York.

Lewis, D.L., Baruch-Mordo, S., Wilson, K.R., Breck, S.W., Mao, J., Broderick, J., 2015. Foraging ecology of black bears in urban environments: guidance for human-bear conflict mitigation. Ecosphere 6, 141.

Lischka, S.A., Riley, S.J., Rudolph, B.A., 2008. Effects of impact perception on acceptance capacity for white-tailed deer. J. Wildl. Manag. 72, 502-509.

Manfredo, M.J., 2008. Who Cares About Wildlife: Social Science Concepts for Exploring Human-Wildlife Relationships and Conservation Issues. Springer Press, New York.

Manfredo, M.J., Teel, T.T., Gavin, M., Fulton, D., 2014. Considerations in representing individuals in social-ecological models. In: Manfredo, M.J., Rechkemmer, A., Vaske, J.J. (Eds.), Understanding Society and Natural Resources: Forging New Strands of Integration Across the Social Sciences. Springer Press, New York.

Manfredo, M.J., et al., 2016. Why social values cannot be changed for the sake of conservation. Conserv. Biol. http://dx.doi.org/10.1111/cobi.12855.

Mascia, M.B., Brosius, J.P., Dobson, T.A., Forbes, B.C., Horowitz, L., McKean, M.A., Turner, N.J., 2003. Conservation and the social sciences. Conserv. Biol. 17, 649-650.

Merkle, J.A., Krausman, P.R., Decesare, N.J., Jonkel, J.J., 2011. Predicting spatial distribution of human-black bear interactions in urban areas. J. Wildl. Manag. 75, 1121-1127.

Miller, C.A., Anderson, W.L., 2002. Digit preference in reported harvest among Illinois waterfowl hunters. Hum. Dimens. Wildl. 7, 55-65.

Morzillo, A.T., de Beurs, K.M., Martin-Mikle, C.J., 2014. A conceptual framework to evaluate human-wildlife interactions within coupled human and natural systems. Ecol. Soc. 19, 11

Obbard, M.E., Howe, E.J., Wall, L.L., Allison, B., Black, R., Davis, P., Dix-Gibson, L., Gatt, M., Hall, M.N., 2014. Relationships among food availability, harvest, and humanbear conflict at landscape scales in Ontario, Canada. Ursus 25, 98-110.

Peterson, M.N., Birckhead, J.L., Leong, K., Peterson, M.J., Peterson, T.R., 2010. Rearticulating the myth of human-wildlife conflict. Conserv. Lett. 3, 74-82.

Pooley, S.P., Mendelsohn, J.A., Milner-Gulland, E.J., 2014. Hunting down the chimera of multiple disciplinarity in conservation science. Conserv. Biol. 28, 22-32.

Redman, C.L., Grove, J.M., Kuby, L.H., 2004. Integrating social science into the long-term ecological research (LTER) network: social dimensions of ecological change and ecological dimensions of social change. Ecosystems 7, 161-171.

Redpath, S.M., et al., 2013. Understanding and managing conservation conflicts. Trends Ecol. Evol. 28, 100-109.

Riley, S., Siemer, W., Decker, D., Carpenter, L., Organ, J., Berchielli, L., 2003. Adaptive impact management: an integrative approach to wildlife management. Hum. Dimens. 
Wildl. 8, 81-095.

Schultz, P.W., 2011. Conservation means behavior. Conserv. Biol. 25, 1080-1083. Tallis, H., Lubchenco, J., 2014. A call for inclusive conservation. Nature 515, 27-28.

Treves, A., Karanth, K.U., 2003. Human-carnivore conflict and perspectives on carnivore management worldwide. Conserv. Biol. 17, 1491-1499.

Treves, A., Kapp, K.J., MacFarland, D.M., 2010. American black bear nuisance complaints and hunter take. Ursus 21, 30-42.

Wieczorek Hudenko, H., 2012. Exploring the influence of emotion on human decision making in human-wildlife conflict. Hum. Dimens. Wildl. 17, 16-28.

Wilbur, R.C., Lischka, S.A., Young, J.R., Johnson, H.E., 2018. Experience, attitudes, and demographic factors influence the probability of reporting human-black bear interactions. Wildl. Soc. Bull. 42, 22-31.

Wong, B.M., Candolin, U., 2015. Behavioral responses to changing environments. Behav. Ecol. 26, 665-673.

Zajac, R.M., Bruskotter, J.T., Wilson, R.S., Prange, S., 2012. Learning to live with black bears: a psychological model of acceptance. J. Wildl. Manag. 76 (7), 1331-1340. 